\title{
Competition Assays to Quantify the Effect of Biocontrol Yeasts against Plant Pathogenic Fungi on Fruits \\ Electine Magoye ${ }^{1}$, Melanie Pfister ${ }^{2}$, Maja Hilber-Bodmer ${ }^{1}$ and Florian M. Freimoser ${ }^{1, *}$
}

\author{
${ }^{1}$ Agroscope, Research Division Plant Protection, Müller-Thurgau-Strasse 29, 8820 Wädenswil, \\ Switzerland; ${ }^{2}$ Swiss Federal Institute of Technology (ETH) Zurich, Zurich, Switzerland \\ *For correspondence: florian.freimoser@agroscope.admin.ch
}

\begin{abstract}
[Abstract] Yeasts such as Aureobasidium pullulans are unicellular fungi that occur in all environments and play important roles in biotechnology, medicine, food and beverage production, research, and agriculture. In the latter, yeasts are explored as biocontrol agents for the control of plant pathogenic fungi (e.g., Botrytis cinerea, Fusarium sp.); mainly on flowers and fruits. Eventually, such yeasts must be evaluated under field conditions, but such trials require a lot of time and resources and are often difficult to control. Experimental systems of intermediate complexity, between in vitro Petri dish assays and field trials, are thus required. For pre- and post-harvest applications, competition assays on fruits are reproducible, economical and thus widely used. Here, we present a general protocol for competition assays with fruits that can be adapted depending on the biocontrol yeast, plant pathogen, type of assay or fruit to be studied.
\end{abstract}

Keywords: Microbiology, Fungi, Yeast, Aureobasidium pullulans, Competition assay, Antagonism, Biocontrol, Plant pathogen, Fruit

[Background] Biocontrol, the use of organisms to control plant pathogens, pests, and weeds, is an attractive alternative to conventional plant protection methods and can help reduce the amount of chemical pesticides employed in agriculture. Most biocontrol organisms are first evaluated in vitro, under laboratory conditions, but eventually will have to prove their efficacy in extensive field trials over many years. Experimental systems which more closely resemble the conditions of an eventual application than a Petri dish and are at the same time, more defined and less time- and resource-demanding than a field trial, are therefore required for both research and the development of novel biocontrol applications.

The bio-protocol presented here represents a combination and adaptation of earlier methods and is specifically aimed at testing the antagonistic activity of yeasts against postharvest diseases of different fruits. Such assays have for example been used to test for antagonistic activity of various yeasts in oranges (Ferraz et al., 2016), cherries (Oro et al., 2014; Gore-Lloyd et al., 2019), peach (Grzegorczyk et al., 2017), nectarines (Janisiewicz et al., 2010), plums (Janisiewicz et al., 2014), pears (Lutz et al., 2012), grapes (Parafati et al., 2015) and apples (Vero et al., 2009). Apart from antagonism testing, a similar method has also been used to assess postharvest disease resistance of apples (Norelli et al., 2017). The protocol can also be adapted for testing the combined application of biocontrol yeasts with antifungal agents, formulation compounds, plant resistance inducers, or other additives that are envisioned to improve biocontrol efficacy (El-Ghaouth et al., 2000; Yu and Zheng, 2006; Yan et al., 2014). 
The method presented here is thus easily reproducible, efficient and extensively adaptable for testing and evaluating disease control in a variety of fruits.

\section{Materials and Reagents}

1. $1.5 \mathrm{ml}$ microcentrifuge tubes (Eppendorf ${ }^{\mathrm{TM}} 3810 \mathrm{X}$ microcentrifuge tubes, Fisher Scientific, catalog number: 10451043)

2. $15 \mathrm{ml}$ centrifuge tubes (Fisherbrand ${ }^{\mathrm{TM}}$ PP Centrifuge Tube, Fisher Scientific, catalog number: 11889640)

3. Hemocytometer cover glasses (Huberlab, $24 \times 24 \times 0.4 \mathrm{~mm}$, catalog number: 10.0440.24)

4. Trays (Thermo Scientific ${ }^{\mathrm{TM}}$ Nalgene ${ }^{\mathrm{TM}}$ Autoclavable Polypropylene Pans, $1260 \times 159 \times 64 \mathrm{~mm}$, catalog number: 6902-1000)

5. Sterile miracloth (autoclaved), pore size 22-25 $\mu \mathrm{m}$ (VWR, Millipore sigma, catalog number: EM475855-1R)

6. Inoculating loops, inoculating sterile disposable loops (VWR, catalog number: 612-9358P)

7. Disposable cuvettes (semi-micro cuvette $10 \times 10 \times 45$ mm, Fisher Scientific, Greiner Bio One, catalog number: 613101)

8. Tissue papers

9. Fruit pack trays (for apple assays)

10. $30 \mathrm{~cm}$ ruler

11. Custom-made consisting of a wooden handle, a metal cover and a metal nail protruding $3 \mathrm{~mm}$ from the tip of the tool; resulting in $3 \mathrm{~mm}$ deep and $2.5 \mathrm{~mm}$ wide lesions

12. Biocontrol yeast (e.g., A. pullulans; available from the Culture Collection of Switzerland under Ccos1008) (maintained at $22^{\circ} \mathrm{C}$ on Potato Dextrose Agar plate (PDA) for $72 \mathrm{~h}$ )

13. Fungal plant pathogen (e.g., B. cinerea (available from the German Collection of Microorganisms and Cell Cultures, DSMZ, under DSM 877), Fusarium sp. (CCOS1020)) (maintained at $22^{\circ} \mathrm{C}$ on PDA for 5-7 days)

14. Whole fruits (e.g., apples, cherries, plums)

15. Potato dextrose agar (CM0139B Potato Dextrose Agar [EP/USP/JP/BP] [Dehydrated], Thermo Scientific ${ }^{\mathrm{TM}}$, catalog number: 10197602)

16. Glycerol

17. $70 \%$ ethanol

18. Distilled water

\section{Equipment}

1. Light microscope (Leitz-Wetzlar; Ortholux)

2. Hemocytometer (Neubauer improved, $0.1 \mathrm{~mm}$ depth, Huberlab, catalog number: 10.0442.04) 
3. Spectrophotometer (GE Healthcare Novaspec ${ }^{\mathrm{TM}}$ III visible spectrophotometer, Fisher Scientific, catalog number: 10773457)

4. Vortex (Ika ${ }^{\circledR}$ vortex, Genius 3, Fisher Scientific, catalog number: 10132562)

5. Micropipette P10, P1000 (Socorex: Acura ${ }^{\circledR}$ manual 825 autoclavable adjustable micropipette)

6. $3 \mathrm{~mm}$ cork drill (cork-drilling kits, Huberlab, catalog number: 13.1118.06)

7. Forceps

8. Wide bottomed measuring cylinder $(3 \mathrm{~L})$

9. $-80^{\circ} \mathrm{C}$ freezer

\section{Procedure}

A. Surface sterilization and preparation of fruits

1. Wipe off any dirt from the fruits using wet tissue paper with $70 \%$ ethanol. As a standard, we use 6 fruits (replicates) for each treatment but, depending on the variability of the assay, more or less replicates may be required.

2. Line the propylene trays with tissue paper and arrange them on a clean surface.

3. Spray $70 \%$ ethanol onto the tissue paper laid out in the trays until the entire tissue surface is covered.

4. Add $1 \mathrm{~L}$ of $70 \%$ ethanol into the $3 \mathrm{~L}$ measuring cylinder.

5. Dip the fruits in $70 \%$ ethanol for 1 min (do not wipe after dipping) by hand (using surface sterilized gloves), gently turn the fruits so that the entire fruit surface is covered, carefully transfer fruits to the sterilized tray by-hand (using surface sterilized gloves).

6. Let them dry for $1 \mathrm{~h}$ in the sterilized trays. Label each tray with the different treatments. When using larger fruits (i.e., apples), apply the label using a permanent marker pen to the fruit itself.

B. Wounding of fruits

1. Sterilize the custom-made tool using $70 \%$ ethanol and use it to create a $2.5 \mathrm{~mm}$ wide and $3 \mathrm{~mm}$ deep wound in each fruit (Figures 1A-1B).

2. Let the inflicted wound dry for $1 \mathrm{~h}$. 

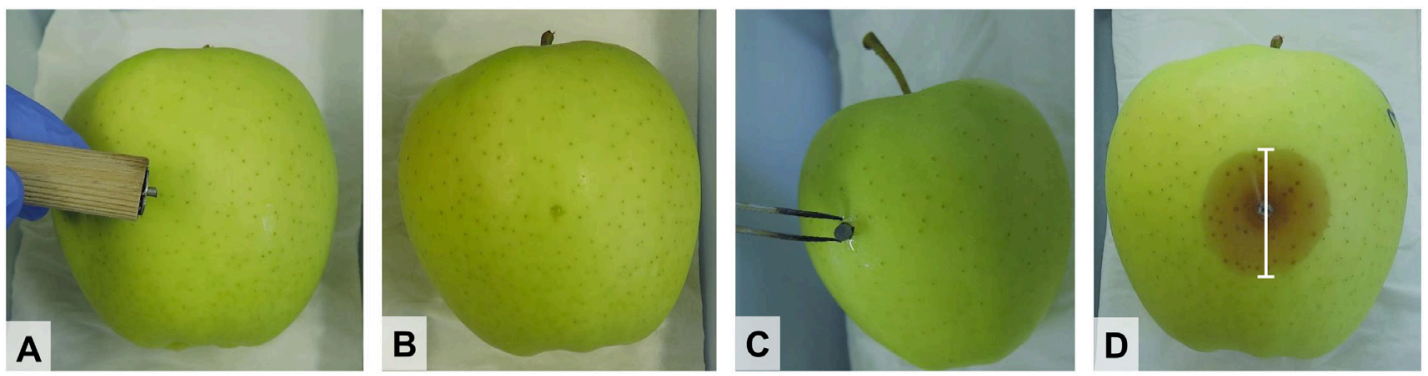

Figure 1. Wounding and infection of an apple fruit using mycelium. A. Wound infliction on an apple using a custom-made tool. B. Wound created before infection. C. Application of mycelium into the wound to start the infection. D. Measuring of the lesion at day 5 post-infection.

\section{Preparation of yeast suspension}

1. Defreeze the biocontrol yeast initially preserved in $30 \%$ glycerol at $-80{ }^{\circ} \mathrm{C}$. Transfer $10 \mu \mathrm{l}$ to a PDA plate and spread using an inoculation loop. Incubate at $22^{\circ} \mathrm{C}$ for $72 \mathrm{~h}$.

2. Using an inoculation loop, pick 5 colonies of the biocontrol yeast cells that have been grown on PDA for $72 \mathrm{~h}$.

3. Transfer the colonies into $1 \mathrm{ml}$ of distilled water.

4. Vortex the suspension for $1 \mathrm{~min}$ or until the yeast cells solution is homogeneous.

5. Dilute the yeast suspension 10 times inside the disposable cuvettes (i.e., mix $100 \mu \mathrm{l}$ yeast solution with $900 \mu$ distilled water).

6. Using the spectrophotometer, measure the absorbance at $600 \mathrm{~nm}\left(\mathrm{OD}_{600}\right)$ and record this $\mathrm{OD}_{600}$ reading.

7. Adjust the cell suspension to a final $\mathrm{OD}_{600}$ of 2 in $1,000 \mu$ l of distilled water as follows:

$$
\text { Volume }_{\text {yeast }}=\frac{\text { Volume }_{\text {final }} \times \text { Final } O D_{600}}{\text { Measured } O D_{600}}
$$

Example: If the $\mathrm{OD}_{600}$ reading is 5.6 , then $357 \mu \mathrm{l}((1,000 \mu \mathrm{l} \times 2) / 5.6)$ of the yeast cell suspension and $643 \mu \mathrm{l}(1,000 \mu \mathrm{l}-357 \mu \mathrm{l})$ of distilled water are mixed in a clean $1.5 \mathrm{ml}$ microcentrifuge tube. Note: The final $O D_{600}$ can vary depending on the yeast, fruit, and pathogen.

D. Yeast application to wounds

1. Add $10 \mu \mathrm{l}$ of the yeast suspension to the wound (ensure the solution is pipetted inside the wound and not flowing out).

2. Let the wounds dry for $3 \mathrm{~h}$ (do not move the trays to avoid yeast solution flowing out of the wound). Depending on the goal of the assay, inoculate yeasts and pathogens simultaneously or give the yeast more time to establish in the wound (i.e., inoculate the pathogen after $3 \mathrm{~h}, 12 \mathrm{~h}$ or 1 day).

Note: Some yeasts may benefit from a longer time to establish before the pathogen is added. 
E. Preparation of the fungal plant pathogen

Defreeze the fungal pathogen mycelium plugs that were initially preserved in $30 \%$ glycerol at $-80^{\circ} \mathrm{C}$. Take out the mycelium plugs using sterile loops and transfer them on a PDA plate. Place 1 mycelium plug per plate (in the center of the plate) and incubate at $22^{\circ} \mathrm{C}$.

Depending on the pathogen of choice, use either conidia or mycelium for infection.

1. Preparation of conidia (e.g., Fusarium sp.)

a. Let the fungus grow on $5 \mathrm{~cm}$ PDA plates (or the medium most suitable to the particular fungal pathogen in question) for 7-14 days depending on the fungal pathogen.

b. Add $10 \mathrm{ml}$ of distilled water onto the $5 \mathrm{~cm}$ PDA plate containing the pathogen.

c. Using the inoculation loop, gently scrape the surface of the plate to suspend the conidia in the water.

d. Filter the conidia using sterile miracloth and collect the filtrate in a sterile $15 \mathrm{ml}$ centrifuge tube.

Note: The conidia are in the filtrate, while hyphae remain in the miracloth.

e. Transfer $1 \mathrm{ml}$ of the filtrate into a $1.5 \mathrm{ml}$ microcentrifuge tube.

f. Clean the glass cover slips and hemocytometer using $70 \%$ ethanol.

g. Place the glass cover slips over the counting chambers of the hemocytometer (apply sufficient force, so that the slide is intact and forms 'Newton colour rings').

h. Pipette $10 \mu \mathrm{l}$ of the conidia suspension between the fixed cover slip and the hemocytometer (pipetting slowly at the edge will allow the solution to seep through).

i. View the hemocytometer under the microscope at magnification 125x (objective 10x, ocular 12.5x).

j. Count the number of conidia in the large corner squares and calculate their density based on the specifications of the specific hemocytometer used.

k. Adjust the concentration of conidia to $5 \times 10^{4}$ conidia per $\mathrm{ml}$ in a defined volume $(1,000 \mu \mathrm{l}$ is usually sufficient) as follows:

$$
\text { Volume }_{\text {Conidia }}=\frac{\text { Volume }_{\text {final }} \times \text { Conidia conentration }_{\text {final }}}{\text { Conidia concentration }_{\text {Calculated }}}
$$

I. Example: If the calculated conidia concentration is $1 \times 10^{5}$ conidia/ml, then $500 \mu \mathrm{l}(1,000 \mu \mathrm{l}$ $\left.\times 5 \times 10^{4} / 1 \times 10^{5}\right)$ of the conidia suspension and $500 \mu \mathrm{l}(1,000 \mu \mathrm{l}-500 \mu \mathrm{l})$ of distilled water are mixed in a $1.5 \mathrm{ml}$ microcentrifuge tube.

Note: The conidia can be stored in $30 \%$ glycerol at $-80{ }^{\circ} \mathrm{C}$ for subsequent use. However, if stored for a longer period they should be tested for viability (plate on PDA medium and after $24 \mathrm{~h}$, microscopically check for germination and growth).

2. Preparation of mycelium (e.g., B. cinerea)

a. Use a 7 days old fungal culture maintained on PDA. 
b. Using a $3 \mathrm{~mm}$ cork drill, careful cut out mycelium plugs from the edge of the colony, where the mycelium is young (Figure 2).
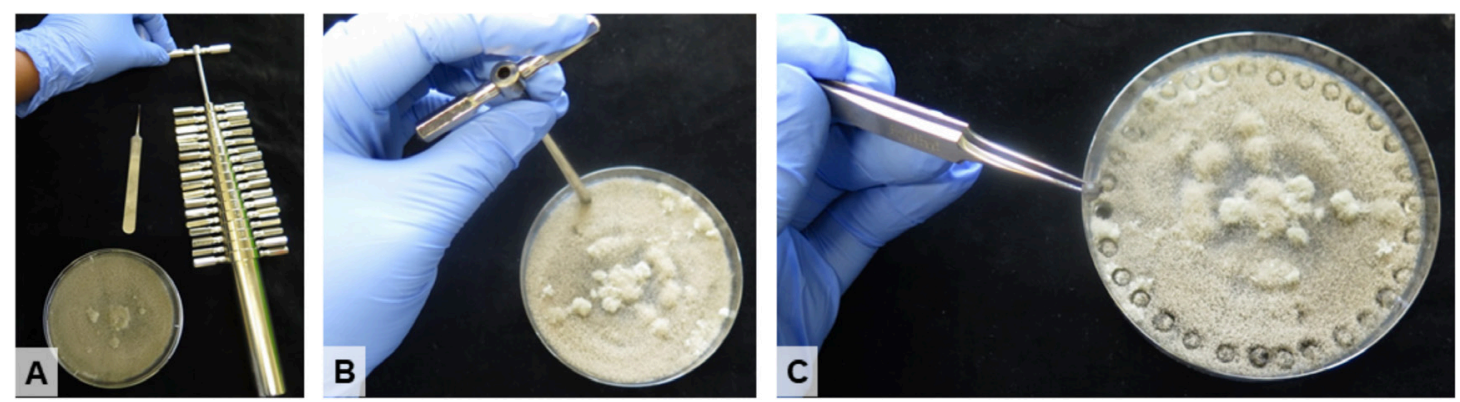

Figure 2. Preparation of mycelium plugs. A. Tools and material needed for mycelium preparation (forceps, cork drill and a pathogen growing on PDA plate). B. Using the $3 \mathrm{~mm}$ cork drill to cut out a mycelium plug. C. A mycelium plug is being picked from the plate using forceps and will be used for wound infection.

\section{F. Wound infection}

1. With conidia

a. Use the conidia suspension with the adjusted concentrations for infection.

b. Carefully pipette $10 \mu \mathrm{l}$ of the conidia solutions into the wound and let it dry for $1 \mathrm{~h}$ (do not move the trays to avoid the pathogen flowing out of the wound).

2. With mycelium

Transfer the mycelium plug using forceps and place it upside down onto the wound (this ensures the mycelium grows into the wound (Figure 1C).

G. Incubation

1. Maintain bigger fruits (e.g., apples, oranges, nectarines) on fruit pack trays. Evenly distribute the different treatments across all boxes and cover the boxes with an autoclave bag. Keep the smaller fruits (e.g., cherries, plums) in plastic incubation boxes that are tightly covered with a lid (in all cases ensure the infected side is facing upwards).

2. Incubate at room temperature for 3-7 days.

Note: Depending on the type and ripeness of the fruit and the pathogen, rotting and lesions will develop at different time points.

H. Evaluation and measurement

1. Measure the diameter of the lesion/rot using a ruler perpendicularly to the stem (Figure 1D)

2. Record the measurement. 


\section{Data analysis}

1. Subtract the diameter of the wound without infection or yeast from all the other recorded values.

2. Calculate the means and the standard deviation for the lesion/rot diameters of each treatment (Table 1).

3. Normalize the means of all the treatments with the 'pathogen only (PO)' treatment by dividing each average value by the average of $\mathrm{PO}$ treatment.

Note: The normalized value for the PO treatment will always be 1, while the value for treatment with biocontrol yeast is ideally less than 1 .

4. Statistically analyze the data (ideally, there should be a statistically significant difference between the pathogen only (PO) treatment and 'biocontrol yeast + pathogen' treatment).

Table 1. The diameter of $B$. cinerea lesions (in $\mathrm{mm}$ ) with various treatments on apple fruits

\begin{tabular}{lllllllllll}
\hline & \multicolumn{1}{c}{ Lesion/rot diameter $(\mathrm{mm})$} & \multicolumn{3}{c}{ Normalized } \\
& $\mathrm{i}$ & ii & iii & iv & v & vi & Mean & SD & Mean & SD \\
\hline Botrytis & 17 & 17 & 22 & 20 & 17 & 16 & 18.2 & 2.3 & 1 & 0.1 \\
Botrytis+ Yeast & 2 & 3 & 2 & 3 & 2 & 1 & $2.2^{*}$ & 0.8 & 0.1 & 0 \\
Yeast & 0 & 0 & 0 & 0 & 0 & 0 & $0.0^{*}$ & 0 & 0 & 0 \\
No infection/yeast & 0 & 0 & 0 & 0 & 0 & 0 & $0.0^{*}$ & 0 & 0 & 0 \\
\hline
\end{tabular}

*Statistically significant mean difference from the pathogen only (PO) treatment.

5. Present the data as histograms, plot the percentage relative size of the lesion Y-axis) and the different treatments (X-axis) (Figure 3 ).

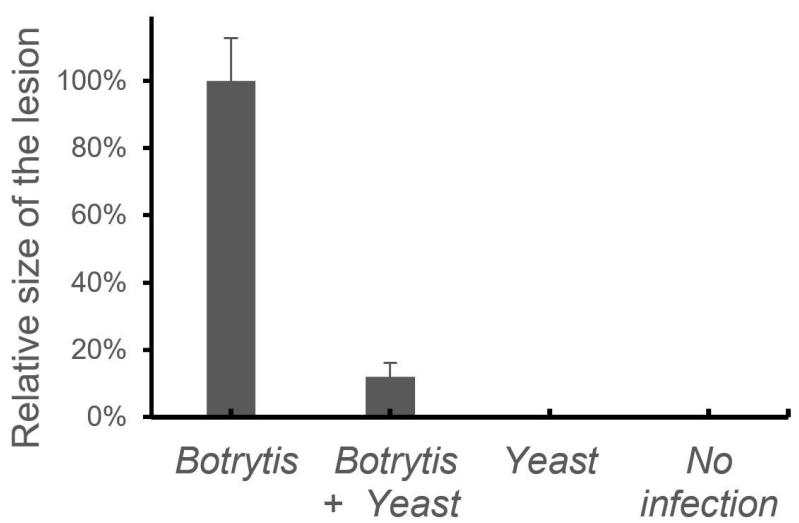

Figure 3. The inhibition of Botrytis lesions in apple fruits in the presence of a biocontrol yeast (A. pullulans). The histogram shows the relative size of Botrytis lesions (normalised means of six independent replicates). Addition of $A$. pullulans to the apple wound suppressed the development of lesions/rot by B. cinerea to $10 \%$. Wounding alone or addition of the yeast alone did not cause the development of a lesion. 


\section{$\underline{\text { Notes }}$}

Although the normalized value for treatment with biocontrol yeast is ideally less than 1 (meaning reduction in pathogen lesion formation upon treatment with a biocontrol yeast), in some cases a value of 1 or more than 1 can be obtained. This is for the case of yeasts that have a stimulatory effect (value larger than 1) or no effect (value of 1) on the pathogen.

\section{Acknowledgments}

This work is supported by Agroscope and the Swiss Expert Committee for Biosafety (SECB) of the Swiss Federal Office for the Environment (FOEN).

\section{Competing interests}

The authors declare no competing interests.

\section{References}

1. El-Ghaouth, A., Smilanick, J. L., Wisniewski, M. and Wilson, C. L. (2000). Improved control of apple and citrus fruit decay with a combination of Candida saitoana and 2-Deoxy-D-glucose. Plant Dis 84(3): 249-253.

2. Ferraz, L. P., Cunha, T. D., da Silva, A. C. and Kupper, K. C. (2016). Biocontrol ability and putative mode of action of yeasts against Geotrichum citri-aurantii in citrus fruit. Microbiol Res 188-189: 72-79.

3. Gore-Lloyd, D., Sumann, I., Brachmann, A. O., Schneeberger, K., Ortiz-Merino, R. A., MorenoBeltran, M., Schläfli, M., Kirner, P., Santos Kron, A., Rueda-Mejia, M. P., Somerville, V., Wolfe, K. H., Piel, J., Ahrens, C. H., Henk, D. and Freimoser, F. M. (2019). Snf2 controls pulcherriminic acid biosynthesis and antifungal activity of the biocontrol yeast Metschnikowia pulcherrima. Mol Microbiol 112(1): 317-332.

4. Grzegorczyk, M., Żarowska, B., Restuccia, C. and Cirvilleri, G. (2017). Postharvest biocontrol ability of killer yeasts against Monilinia fructigena and Monilinia fructicola on stone fruit. Food Microbiol 61: 93-101.

5. Janisiewicz, W. J., Jurick, W. M., 2nd, Peter, K. A., Kurtzman, C. P. and Buyer, J. S. (2014). Yeasts associated with plums and their potential for controlling brown rot after harvest. Yeast 31(6): 207-218.

6. Janisiewicz, W. J., Kurtzman, C. P. and Buyer, J. S. (2010). Yeasts associated with nectarines and their potential for biological control of brown rot. Yeast 27(7): 389-398.

7. Lutz, M. C., Lopes, C. A., Sosa, M. C. and Sangorrín, M. P. (2012). A new improved strategy for the selection of cold-adapted antagonist yeasts to control postharvest pear diseases. Biocontrol 
Sci Techn 22(12): 1465-1483.

8. Norelli, J. L., Wisniewski, M., Fazio, G., Burchard, E., Gutierrez, B., Levin, E. and Droby, S. (2017). Genotyping-by-sequencing markers facilitate the identification of quantitative trait loci controlling resistance to Penicillium expansum in Malus sieversii. PLoS One 12(3): e0172949.

9. Oro, L., Feliziani, E., Ciani, M., Romanazzi, G. and Comitini, F. (2014). Biocontrol of postharvest brown rot of sweet cherries by Saccharomyces cerevisiae Disva 599, Metschnikowia pulcherrima Disva 267 and Wickerhamomyces anomalus Disva 2 strains. Postharvest Biol Techn 96: 64-68.

10. Parafati, L., Vitale, A., Restuccia, C. and Cirvilleri, G. (2015). Biocontrol ability and action mechanism of food-isolated yeast strains against Botrytis cinerea causing post-harvest bunch rot of table grape. Food Microbiol 47: 85-92.

11. Vero, S., Garmendia, G., González, M. B., Garat, M. F. and Wisniewski, M. (2009). Aureobasidium pullulans as a biocontrol agent of postharvest pathogens of apples in Uruguay. Biocontrol Sci Techn 19(10): 1033-1049.

12. Yan, F., Xu, S., Chen, Y., and Zheng, X. (2014). Effect of rhamnolipids on Rhodotorula glutinis biocontrol of Alternaria alternata infection in cherry tomato fruit. Postharvest Biol Techn 97: 3235.

13. Yu, T. and Zheng, X. D. (2006). Salicylic acid enhances biocontrol efficacy of the antagonist Cryptococcus laurentii in apple fruit. J Plant Growth Regul 25(2): 166-174. 